\title{
Prevalence of gestational diabetes mellitus and associated factors in Southern Ethiopia
}

\author{
Eskinder Wolka', Wakgari Deressa ${ }^{2}$, Ahmed Reja ${ }^{3}$ \\ ${ }^{1}$ Assistant Professor, School of Public Health, College of Health Sciences and Medicine, Wolaita Sodo University, \\ Wolaita Sodo, Ethiopia, ${ }^{2}$ Associate Professor, School of Public Health, College of Health Sciences, Addis Ababa \\ University, Addis Ababa, Ethiopia, ${ }^{3}$ Consultant Physician and Assistant Professor, School of Medicine, College of \\ Health Sciences, Addis Ababa University, Addis Ababa, Ethiopia
}

\section{A B S T R A C T}

Background: Presence of gestational diabetes mellitus during pregnancy has serious complications for both mother and child. Its burden is increasing in low and middle-income countries but, little is known about its contribution in Ethiopia.

Aims and Objective: The aim of this study was to determine the prevalence of gestational diabetes mellitus and to identify associated factors in Wolaita Zone, Southern Ethiopia.

Materials and Methods: Institution based cross sectional study was carried out from August to October 2017 in Wolaita Zone, southern Ethiopia. A total of 518 pregnant women were participated from 2 hospitals and 4 health centers. Capillary blood samples were collected at fasting and 2 hours after $75 \mathrm{gm}$ glucose load to measure blood sugar and diagnosis of gestational diabetes mellitus was made by using 2013 World Health Organization (WHO) criteria. Binary logistic regression model was applied to assess risk factors of gestational diabetes mellitus.

\section{Access this article online}

Website:

http://nepjol.info/index.php/AJMS DOI: 10.3126/ajms.v10i1.21331 E-ISSN: 2091-0576 P-ISSN: 2467-9100

Results: Prevalence of gestational diabetes mellitus was $4.2 \%(95 \% \mathrm{Cl}, 2.5,6.2)$ with mean post glucose load level of $160.1 \mathrm{mg} / \mathrm{dl}(6.3)$ and $15(4 \%)$ among urban residents and $7(4.9 \%)$ among rural residents. The proportion of gestational diabetes mellitus increases with increase in number of pregnancies.Previous history of spontaneous abortion (AOR: 3.5; $95 \% \mathrm{Cl}: 1.7-14.6$ ), family history of type II diabetes (AOR: $4.3 ; 95 \% \mathrm{Cl}: 1.3-8.7$ ) and previous caesarean section (AOR: $7.5 ; 95 \% \mathrm{Cl}: 1.3-14.4$ ) were found to be significantly associated with gestational diabetes mellitus.

Conclusions: The prevalence of gestational diabetes mellitus is higher as compared to other studies conducted in the country. Strengthening screening, care and prevention strategies for gestational diabetes mellitus are important to improve maternal and child health.

Key words: Gestational diabetes mellitus; Southern Ethiopia; Diabetes in pregnancy; Wolaita Zone

\section{INTRODUCTION}

Gestational diabetes mellitus (GDM) is a glucose intolerance of altering degrees of seriousness which starts or identified for first time during pregnancy. ${ }^{1}$ Globally, prevalence of hyper-glycaemia in pregnancy among women of reproductive age group was approximated to be $16.9 \%$ and, about $90 \%$ of cases were estimated to happen in developing countries. ${ }^{1}$

The health situation of pregnant mother with diabetes and her unborn child can be endangered with different levels of complications. These complications can lead to death in worst situations. ${ }^{2}$

Gestational diabetes mellitus has also long-term public health importance. It contributes to the rising type 2 diabetes epidemic. It is a momentary phenomenon for the pregnant mother, but more than $50 \%$ of the women develop type 2 diabetes in future life and the tendency of their children to develop obesity as young children and type 2 diabetes later on is found to be higher. ${ }^{3}$ 
The magnitude of GDM differs across countries based on some reasons like ethnic groups, life style, level of educational, family history of diabetes and many other factors. ${ }^{4}$

The most common cause of hyperglycaemia occurring during pregnancy is GDM, and its contribution is about $90 \%$ of all diabetes during pregnancy. ${ }^{5}$ It has been reported that GDM affects up to about 1 in 10pregnancies, and its prevalence has been progressively increasing. ${ }^{6}$

Currently, availability of factors like changes in life style, dietary habits, urbanization, physical inactivity, the tendency towards delayed marriage and older maternal age in different parts of the globe are making favourable ground and the prevalence of GDM may very well be on the rise. ${ }^{7}$

Because of cost, numerous countries in Africa detect blood glucose level of pregnant women to diagnose GDM based on identified risk factors selectively and the proportion of women suffering from the caseand the magnitude of the problem are unclear. ${ }^{8}$

In Ethiopia, although diabetes mellitus is recognized as one of the major non-communicable diseases, the magnitude of GDM among pregnant mothers and factors associated with it were not well researched.

Identifying the prevalence of the problem and common risk factors would be important to mitigate the problem on timely bases and helpful to health policy and program improvement.

Therefore, the study aimed to identify the prevalence of gestational diabetes mellitus among pregnant mothers and associated factors in Southern region of Ethiopia.

\section{MATERIALS AND METHODS}

The study was conducted in Southern part of Ethiopia from August 2017 to October 2017. The study site is one of the nine regions in Ethiopia and it consists of many different languages and ethnic groups within own diverse culture. The area of the region covers $10 \%$ of the national landmass and its boundary shows; there is Kenya to the south, Sudan to the southwest, Gambela regional state of Ethiopia to the west and Oromia regional state of Ethiopia to the Northand North-East. The region is composed of 13 zones and of which Wolaita Zone is the one and situated in the south central part of the region, $330 \mathrm{~km}$ distance from Addis Ababa. The Zone has total population of about 2 million in 2017 as projected from 2007 national census. Wolaita zone is one of the most densely populated areas in the country with an average of 640 people living per square kilometre. There are 3 Hospitals, 70 health centers and 380 health posts in the study area and among these 12 Health Centers and all three hospitals provide diagnostic and management service for pregnant women with diabetes mellitus. ${ }^{9}$

Cross sectional study design was employed. Mothers with gestational age of 24-28 weeks who were attending antenatal care service in selected 2 hospitals and 4 health centers during the survey period were included. The health facilities were selected randomly from total facilities providing treatment and care for pregnant women with gestational diabetes. The proportion from study conducted in Northern Ethiopia was used to calculate sample size. ${ }^{10}$ Our assessment involved 518 eligible mothers and all of them were willing for blood glucose level test. Women with previously diagnosed diabetes were excluded from the study. All mothers attending antenatal care service in the selected health facilities within study period were screened for GDM.

Structured questionnaire was used, and details pertaining to socio-demography, family history, medical and obstetric history were collected. Blood pressure was measured, 75 gm oral glucose administered, capillary glucose level was measured at $0 \mathrm{hr}$ and $2 \mathrm{hr}$ using HemoCue Glucose and GDM was diagnosed based on 2013 WHO criteria. ${ }^{11}$

We used Epi Info 7 and STATA 14 (StataCorp, College Station, TX, USA) programs for data entry and analysis. Descriptive figures, frequency and percentages were calculated. Tables and figures were used to show descriptive findings. Multivariable logistic regression model was used to compute adjusted odds ratio and to evaluate the relationship between variables. $P$-values less than. 05 were considered for statistical significance.

The study was approved by Institutional Review Board of Addis Ababa University. Wolaita Zone health department wrote letter of support and confirmed their willingness to conduct the research prior to the study. We got written consent from all participants before starting any component of data collection. Confidentiality was clarified and guaranteed. Women diagnosed with GDM and other medical problems were referred to appropriate care and management.

\section{RESULTS}

\section{Socio demographic Characteristics}

Total sample size required for the study was 564, among these 518 pregnant women participated in the study and making the response rate of $91.8 \%$. Of 518 women 
included in the study, 376(72.6\%) were urban residents. Majority, 388(74.9\%), were 21-30 years old. The mean age was 25.7 (4.4), nearly all, 506(97.7) were married. Most of the mothers, $422(81.5 \%)$, were from Wolaita ethnic group and $89(17.2 \%)$ had not attended any formal education. Nearly half, $242(46.7 \%)$ were housewives and working as government employee is the leading occupation of their partners, 205(40.5\%) (Table 1).

\section{Obstetric characteristic of respondents}

Basic obstetric characteristics were assessed in this study. Screening of GDM was carried out at 24 to 28 gestational weeks. Of the 518 study participants, majority, $372(71.8 \%)$ had two or more pregnancies, with mean gestational age of 26 weeks. More than one third of the respondents, 187(36.1\%), were multi-para. Out of 372 mothers who had two or more pregnancies, $45(12.1 \%)$ had previous history of still birth, $67(18 \%)$ had previous history of abortion, and caesarean section rate was $16.1 \%$ (Table 2).

\section{Prevalence of GDM}

Overall prevalence of gestational diabetes mellitus was $4.2 \%$ with mean post glucose load level of $160.1 \mathrm{mg} / \mathrm{dl}$ (6.3) and 15(4\%) among urban residents and 7(4.9\%) among rural residents. The proportion of gestational diabetes mellitus increases with increase in number of pregnancies (Figure 1).

Gestational diabetes mellitus was more common in multiparaous pregnant women, GDM was diagnosed in $4(2.3 \%)$ of primiparaous, $7(4.5 \%)$ of multiparaous and $11(33.3 \%)$ of grand multiparaous mothers and in other words $18 \%, 32 \%$ and $50 \%$ of total diagnosed cases were primiparaous, multiparaous and grand multiparaous mothers respectively.

Risk factors associated with gestational diabetes mellitus

Factors associated with GDM were identified by using binary logistic regression model. In bivariate logistic regression model, previous history of still birth (COR:4.8; 95\%CI:1.9-12.3), previous history of spontaneous abortion (COR: 4.2; 95\%CI: 1.8-10.4), family history of type II diabetes (AOR:6.2; 95\%CI: 1.4-9.8) andprevious caesarean section (COR: 7.5 ; 95\%CI: 3.1-18.4) were identified to be statistically significant.

Multivariable analysis was used to control potential confounders. Accordingly, previous history of spontaneous abortion (AOR: 3.5; 95\% CI: 1.7-14.6), family history of type II diabetes (AOR: 4.3; 95\%CI: 1.3-8.7) andprevious caesarean section (AOR: 7.5; 95\%CI: 1.3-14.4) were found to be independently associated (Table 3 ).

\begin{tabular}{|c|c|c|}
\hline Characteristics & Number & Percent \\
\hline \multicolumn{3}{|l|}{ Age $(n=518)$} \\
\hline $16-20$ & 77 & 14.9 \\
\hline $21-25$ & 206 & 39.8 \\
\hline $26-30$ & 182 & 35.1 \\
\hline $31-35$ & 41 & 7.9 \\
\hline$>35$ & 12 & 2.3 \\
\hline \multicolumn{3}{|l|}{ Residence $(n=518)$} \\
\hline Urban & 376 & 72.6 \\
\hline Rural & 142 & 27.4 \\
\hline \multicolumn{3}{|l|}{ Marital status $(n=518)$} \\
\hline Married & 506 & 97.7 \\
\hline Single/divorced/widowed & 12 & 2.3 \\
\hline \multicolumn{3}{|l|}{ Religion $(n=518)$} \\
\hline Protestant & 342 & 66 \\
\hline Orthodox & 137 & 26.4 \\
\hline Muslim & 17 & 3.3 \\
\hline Catholic & 11 & 2.1 \\
\hline Others+ + & 11 & 2.1 \\
\hline \multicolumn{3}{|l|}{ Ethnicity $(n=518)$} \\
\hline Wolaita & 422 & 81.5 \\
\hline Amhara & 47 & 9.1 \\
\hline Gamo & 27 & 5.2 \\
\hline Guraghe & 12 & 2.3 \\
\hline Others ++ & 10 & 1.9 \\
\hline \multicolumn{3}{|l|}{ Education of mother $(n=518)$} \\
\hline No formal education & 89 & 17.2 \\
\hline Primary & 124 & 23.9 \\
\hline Secondary & 150 & 29.0 \\
\hline Post- secondary & 155 & 29.9 \\
\hline \multicolumn{3}{|c|}{ Occupation of mother $(n=518)$} \\
\hline House wife & 242 & 46.7 \\
\hline Government employee & 174 & 33.6 \\
\hline Petty trade & 60 & 11.6 \\
\hline NGO employee & 26 & 5.0 \\
\hline Daily laborer & 16 & 3.1 \\
\hline \multicolumn{3}{|l|}{ Spouse's education $(n=506)$} \\
\hline No formal education & 70 & 13.8 \\
\hline Primary & 101 & 20.0 \\
\hline Secondary & 127 & 25.1 \\
\hline Post -secondary & 208 & 41.4 \\
\hline \multicolumn{3}{|l|}{ Spouse's occupation ( $n=506)$} \\
\hline Government employee & 205 & 40.5 \\
\hline Petty trade & 137 & 27.1 \\
\hline NGO employee & 55 & 10.9 \\
\hline Daily laborer & 82 & 16.2 \\
\hline Others+++ & 27 & 5.3 \\
\hline
\end{tabular}

+ Apostolic, Traditional++Oromo, Tigrie, Silte +++ Farmer, Broker

\section{DISCUSSION}

The core purpose of this study was to measure the prevalence of GDM and to identify factors associated with it in Wolaita Zone, Southern Ethiopia. Total of 518 pregnant women with duration of 24-28 weeks of pregnancy were examined for gestational diabetes mellitus by using WHO 2013 recommendation. The overall prevalence of gestational diabetes mellitus was $4.2 \%, 15$ (4\%) among urban residents and 7(4.9\%) among rural 


\begin{tabular}{|c|c|c|}
\hline Characteristics & Number & Percent \\
\hline \multicolumn{3}{|l|}{ Gravidity } \\
\hline One & 146 & 28.2 \\
\hline Two & 164 & 31.7 \\
\hline Three & 107 & 20.7 \\
\hline Four & 57 & 11.0 \\
\hline Five or more & 44 & 8.5 \\
\hline \multicolumn{3}{|l|}{ Parity } \\
\hline Nullipara & 154 & 29.7 \\
\hline Para one & 177 & 34.2 \\
\hline Multipara (2-4) & 154 & 29.7 \\
\hline Grandmultipara (>5) & 33 & 6.4 \\
\hline \multicolumn{3}{|l|}{ Gestational age in weeks } \\
\hline 24 & 124 & 23.9 \\
\hline 25 & 86 & 16.6 \\
\hline 26 & 88 & 17.0 \\
\hline 27 & 93 & 18.0 \\
\hline 28 & 127 & 24.5 \\
\hline \multicolumn{3}{|c|}{ Birth weight of previous child $(n=308)$} \\
\hline Less than $2.5 \mathrm{~kg}$ & 12 & 3.8 \\
\hline $2.5-3.9 \mathrm{~kg}$ & 236 & 76.6 \\
\hline $4 \mathrm{~kg}$ or more & 60 & 19.5 \\
\hline \multicolumn{3}{|c|}{ Previous still birth $(\mathrm{n}=372)$} \\
\hline Yes & 45 & 12.1 \\
\hline No & 327 & 87.9 \\
\hline \multicolumn{3}{|c|}{ Previous abortion $(n=372)$} \\
\hline Yes & 67 & 18.0 \\
\hline No & 305 & 82.0 \\
\hline \multicolumn{3}{|c|}{ Previous caesarean section $(n=372)$} \\
\hline Yes & 60 & 16.1 \\
\hline No & 312 & 83.9 \\
\hline \multicolumn{3}{|c|}{ Previous history of GDM $(n=372)$} \\
\hline Yes & 19 & 5.1 \\
\hline No & 353 & 94.9 \\
\hline \multicolumn{3}{|c|}{ Family history of type II DM ( $n=416)$} \\
\hline Yes & 57 & 13.7 \\
\hline No & 359 & 86.3 \\
\hline
\end{tabular}

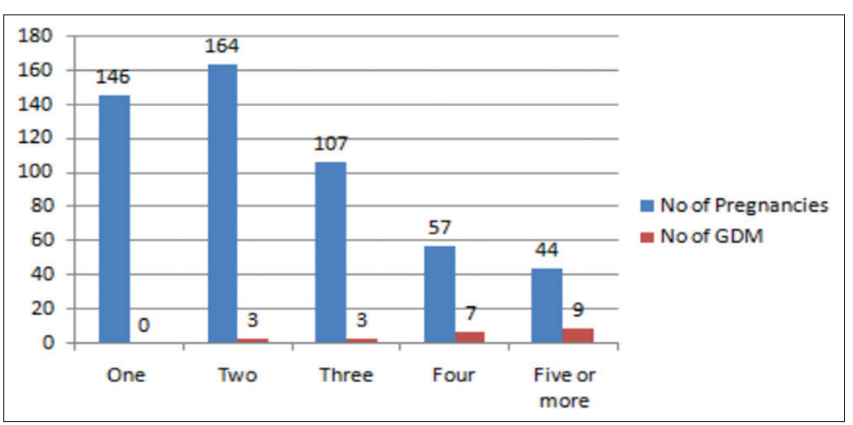

Figure 1: Number of Pregnancies and corresponding number of gestational diabetes mellitus of respondents in Wolaita Zone, Southern Ethiopia, 2017

residents which is relatively higher than previous point estimate of study conducted in Northern Ethiopia. ${ }^{10} \mathrm{It}$ is also reported that GDM is increasing in most parts of the world during the past 20 years among several groups of population. ${ }^{7}$ This finding is almost comparable with findings of studies in Sri Lanka and Nigeria ${ }^{12,13}$ but lower than some other countries' studies like India ${ }^{14}$, Qatar ${ }^{15}$, Argentina ${ }^{16}$, Pakistan ${ }^{17}$ and Tanzania. ${ }^{18}$ Differences in prevalence of gestational diabetes mellitus among different countries can be related to differences in socio-economic status, life style and variations in screening and diagnostic methods. Differences in screening technique and use of various diagnostic criteria have enacted difficulty in comparing the situation of GDM across countries; despite this fact, ourfinding indicates that the magnitudeof the problem is increasing in the area.

In our study, the proportion of gestational diabetes mellitus increases with increase in number of pregnancies and was more common in multiparaous pregnant women; similar finding was reported by the study done in Qatar and it was indicated that the risk of GDM increases with number of pregnancy. ${ }^{19}$

In this study, GDM was associated with previous history of abortion; the odds of developing GDM was 3.5 times higher among women with previous history of abortion when compared with those who had no history of spontaneous abortion. This result is consistent with other study conducted in China and the study mentioned that previous history of spontaneous abortion was linked with elevatedpossibility of acquiring GDM. ${ }^{20}$

Family history of type II diabetes mellitus was linked with the occurrence of GDM. From other evidence,those mother with positive family history of type II diabetes mellitus have higher risk of developing GDM. ${ }^{21}$

Previous history of caesarean section wasindependently predictor of gestational diabetes mellitus. This result is consistent with studies conducted in different countries. A study conducted in South Eastern Nigeria suggested that there is a significant relationship between previous history of caesarean delivery and occurrence of gestational diabetes. ${ }^{22}$ Similar findings have been stated in studies conducted in Tanzania ${ }^{17}$ and India ${ }^{23}$, GDM was significantly associated with previous history of caesarean sections. There was no statistically significant association between mid-upper arm circumference and high blood pressure with occurrence of GDM.

\section{CONCLUSION}

The finding of this study point out that, the prevalence of GDM is higher as compared to other studies conducted in the country. The proportion of gestational diabetes mellitus increases with increase in number of pregnancies and was more common in multiparaous pregnant women. Previous histories of spontaneous abortion, family history of type II 
Table 3: Bivariate and multivariate logistic analysis of factors associated with gestational diabetes mellitus among participants, Wolaita zone, Southern Ethiopia, 2017

\begin{tabular}{|c|c|c|c|c|c|}
\hline \multirow[t]{2}{*}{ Variable } & \multirow[t]{2}{*}{ Category } & \multicolumn{2}{|c|}{ Gestational diabetes mellitus } & \multirow[t]{2}{*}{ COR $(95 \% \mathrm{Cl})$} & \multirow[t]{2}{*}{ AOR $(95 \% \mathrm{Cl})$} \\
\hline & & Yes N (\%) & No $N(\%)$ & & \\
\hline \multirow[t]{2}{*}{ Residence } & Urban & $15(4)$ & $361(96)$ & $0.8(0.3,2.0)$ & $3.6(0.4,13.6)$ \\
\hline & Rural & $7(4.9)$ & 135 (98.1) & 1 & 1 \\
\hline \multirow[t]{2}{*}{ Previous still birth } & Yes & $8(36.4)$ & $37(10.6)$ & $4.8(1.9,12.3)$ & $2.8(0.2,3.5)$ \\
\hline & No & $14(63.6)$ & 313 (89.4) & 1 & 1 \\
\hline \multirow[t]{2}{*}{ Previous spontaneous abortion } & Yes & $10(45.5)$ & $57(16.3)$ & $4.2(1.8,10.4)^{*}$ & $3.5(1.7,14.6)^{*}$ \\
\hline & No & $12(54.5)$ & $293(83.7)$ & 1 & 1 \\
\hline \multirow[t]{2}{*}{ Birth weight of previous child } & Less than 3999 & $14(63.6)$ & $228(81.4)$ & 1 & 1 \\
\hline & 4000 gm or more & $8(36.4)$ & $52(18.6)$ & $0.4(0.2,1.2)$ & $0.7(0.5,1.8)$ \\
\hline \multirow[t]{2}{*}{ Previous caesarean section } & Yes & $12(54.5)$ & $48(13.7)$ & $7.5(3.1,18.4)^{*}$ & $7.5(1.3,14.4)^{*}$ \\
\hline & No & $10(45.5)$ & $302(86.3)$ & 1 & 1 \\
\hline \multirow[t]{2}{*}{ Family history of type II DM } & Yes & $11(50)$ & 57 (13.7) & $6.2(1.4,9.8)^{*}$ & $4.3(1.3,8.7)^{*}$ \\
\hline & No & $11(50)$ & $359(86.3)$ & 1 & 1 \\
\hline \multirow[t]{2}{*}{ MUAC } & Less than $28 \mathrm{~cm}$ & $13(59.1)$ & $346(69.8)$ & 1 & 1 \\
\hline & More than $28 \mathrm{~cm}$ & $9(40.9)$ & $150(30.2)$ & $0.6(0.3,1.5)$ & $0.9(0.1,1.8)$ \\
\hline
\end{tabular}

diabetes mellitus and previous caesarean delivery were found to be risk factors of gestational diabetes. Health care providers should promote blood glucose level testing and strengthen gestational diabetes mellitus screening based on risk factors and putting preventive measures in place is helpful to prevent long term effects of GDM on the mother and newborn.

\section{ACKNOWLEDGEMENT}

Study participants, Addis Ababa University and Wolaita Sodo University.

\section{REFERENCES}

1. International Diabetes Federation: Diabetes Atlas. Brussels, Belgium, 2013.

2. Moore T and Smith C. Diabetes Mellitus and Pregnancy. Medscape drugs, diseases and procedures 2012. Available from: URL: http:// emedicine.medscape.com/article/127 547-overview [2013].

3. Kim C. Gestational diabetes: risks, management, and treatment options. Int J Womens' Health 2010; 2:339-351.

4. Moses RG, Moses J and Davis WS. Gestational Diabetes. Do Lean Young Caucasian Women Need to be Tested? Diabetes Care 1998; 21(11):1803-1806.

5. American Diabetes Association, Diagnosis and Classification of Diabetes Mellitus. Diabtes Care 2004; 24: 5-10.

6. American Diabetes Association. Diagnosis and classification of diabetes mellitus. Diabetes Care 2007; 149: 196-204.

7. Ferrara A. Increasing prevalence of gestational diabetes mellitus: a public health perspective. Diabetes Care 2007:141-146.

8. Jiwani A, Marseille E, Lohse N, Damm P, Hod M and Kahn JG. Gestational diabetes mellitus: results from a survey of country prevalence and practices. J Matern Fetal Neonatal Med 2012; 25(6):600-610.

9. Wolaita Zone Health Department. Annual Report 2016.

10. Seyoum B, Kiros K, Haileselase $T$ and Leole A. Prevalence of gestational diabetes mellitus in rural pregnant mothers in northern Ethiopia. Diabetes Res Clin Pract 1999; 46:247-251.
11. Diagnostic criteria and classification of hyperglycaemia first detected in pregnancy: a World Health Organization Guideline. Diabetes Res Clin Pract 2014; 103: 341-363.

12. Siribaddana SH, Deshabandu R. Rajapakse D, Silva K and Fernando DJ. The prevalence of gestational diabetes in a Sri Lankan antenatal clinic. Ceylon Med J 1998;43(2):88-91.

13. Olarinoye JK, Ohwovoriole AE and Ajayi GO. Diagnosis of gestational diabetes mellitus in Nigerian pregnant women. West Afr J Med 2004; 23(3):198-201.

14. Wahi P, Dogra V, Jandial K, Bhagat R, Gupta R, Gupta S, et al, Prevalence of gestational diabetes mellitus and its outcomes in Jammu region. J Assoc Physicians India 2011; 59:227-230.

15. Bener A, Saleh NM and Al-Hamag A. Prevalence of gestational diabetes and associated maternal and neonatal complications in a fast-developing community: global comparisons. Int JWomens' Health 2011; 3: 367-373.

16. McCarthy A, Curcuarello R, Castillione N, Tayeldin M, Costa D, Arnol V, et al. Universal versus selective screening for the detection, control and prognosis of gestational diabetes mellitus in Argentina. Acta Diabetol 2010; 47(2):97-103.

17. Bibi S, Saleem $U$, and Mahsood N. The frequency of gestational diabetes mellitus and associated risk factors at Khyber teaching hospital Peshawar. J Postgrad Med Inst2015; 29(1):43-46.

18. AkwilinaW, Kinabo J, Ramaiya $\mathrm{K}$ and Feskens EJ. Prevalence of Gestational Diabetes Mellitus (GDM) and Associated Determinants in Urban and Rural Tanzania. Diabetes Res Clin Pract 2014. 103(1): 71-78.

19. Mohamed GA, Bodour S and AlKubaisi A. Prevalence and Predictors of Gestational Diabetes Mellitus in Qatar. Diabetologia Croatica 2011; 40(3):65-70.

20. Yang H, Wei Y, Gao X, Xu X, Fan L, He J, et al. Risk factors for gestational diabetes mellitus in Chinese women a prospective study of 16286 pregnant women in China. Diabet Med 2009; 26(11):1099-1104.

21. American Diabetes Association. Gestational diabetes mellitus. Diabetes Care 2003;26:S103-S105.

22. Nwaokoro JC, Emerole CO, Ibe SNO, Amadi AN and Dozie INS. Risk Factors Associated with Gestational Diabetes among Pregnant Women in Owerri Municipal Council, Southeastern Nigeria. Asian Journal of Medical Science2014; 5(1):39-46.

23. Goud TG, Kumar P and Ramesh K. Risk factors of Gestational Diabetes in Karnataka.Int J Cur Res Aca Rev 2014;2(9):286-291. 
Authors Contribution:

EW- Conceived and designed the study, reviewed the literature, performed analysis and interpretation of data, prepared the manuscript and critical revision of the manuscript; WD- Assisted with the study design, analysis and interpretation and critical revision of the manuscript; AR- Assisted interpretation and critical revision of the manuscript.

Orcid ID:

Eskinder Wolka - (D) https://orcid.org/0000-0003-1720-7561

Wakgari Deressa - io https://orcid.org/0000-0002-9712-2375

Ahmed Reja- io https://orcid.org/0000-0002-1154-0390

Source of Funding: Nil, Conflict of Interest: None. 